Vol. 17 No. 34 Juli - Desember 2018

\title{
Kredit Bermasalah Di Perbankan Syari'ah dalam Perspektif Teori Cacat Kehendak
}

\author{
Ahmad Gazali \\ UIN Antasari Banjarmasin
}

\begin{abstract}
The development of Islamic banking, especially in Indonesia, is currently very perspective. Therefore there is trust from the community must always be maintained. Efforts to develop and trust must support two aspects, namely the implementation of transparency with Islamic ethics and a sense of foundation that provides certainty and a sense of justice. As a sharia banking, the operational basis is Islamic law, thus the readiness of Islamic law must always exist and be able to overcome the development of the development of the Islamic banking world. This paper is only a small part of the discussion to be approved and legal norms of sharia banking are made.
\end{abstract}

Keywords: Sharia Banking; Banking Credit; Willing Disabilities

\section{Pendahuluan}

Keberadaan sistem perbankan syari'ah dalam negeri RI telah dialami. Hal ini terbukti dengan diaturnya sistem bank syari'ah dalam UU No 7 tahun 1992 tentang perbangkan yang kemudian diperkuat dengan UU No 10 tahun 1998 serta UU No 8 tahun 1998 dan UU No 23 tahun 1999 tentang Bank Indonesia.

Menurut penelitian yang dilakukan oleh BI, Perspektif Masyarakat Terhadap Bank Syari'ah adalah: Bank dengan sistem bagi hasil tanpa bunga, bank bagi umat Islam dan bank yang dilandasi kejujuran dan etika dan rapuh rapuh pemahaman agama. Dengan persepsi yang seperti ini perkembangan dunia perbankan syariah di 
Indonesia dan kenerjanya cukup menggembirakan. Sebagai contoh di saat bank-bank konvensional berdarah-darah ditimpa badai krisis pada tahun 1998, bank syariah dalam hal ini Bank Muamalat Indonesia (BMI) tetap teguh berdiri : pada tahu 1999 Bank Muamalat bahkan meraih laba bersih Rp. 2 Miliar, di saat yang sama perbankan konvensional meraih dalam konsulidasi internal untuk pemulihan.

Kendati demikian dalam perspektif idealistik keadaan seperti ini tetap saja masih jauh dari diharapkan, sebab problema perbankkan kedua kali jauh lebih parah dari apa yang dipredeksikan, apalagi dalam dunia. Perbankan syariah yang pada dasarnya bertumpu pada prinsip-prinsip syariah dan berada di jalan yang belum di atur oleh UU perbankkan negara.

Dengan demikian penulis dapat menyatakan bahwa penelitian atau tulisan yang sama dengan tulisan ini jarang dibicarakan. Karena penulisa lebih memfukuskan pada masalah kredit bermasalah yang dilihat dari perspektif hukum Islam terutama kaitannya dengan utang piutang.

\section{Pembahasan}

\section{Kredit dan Utang Piutang}

Kredit bermasalah adalah kredit yang dalam pelaksanaanya terjadi cedera janji baik berupa teterlambatan membayar atau ketidak mampuan membayar utang kredit sama sekali. Untuk menjawab permasalahan tersebut penulis akan meletekannya dalam kerangkan teori utang piutang dan cacat kehendak dalam transaksi dalam hukum Islam.

a. Utang-Piutang

Islam sebagai agama universal mengandung ajaran-ajaran dasar yang berlaku untuk semua tempat dan waktu. Ajaran yang bersifat dasar dan universal itu, menurut para ulama hanya terdapat pada 
sekitar 500 ayat atau (14\%) dari keseluruhan ayat Al-Qur'an. ${ }^{1}$ Walaupun bersifat absolut, tetapi dalam aspek hukum Islam mempunyai prinsip-prinsip yang luas yang dapat mengakomodasi setiap perubahan dalam kehidupan sosial manusia. ${ }^{2}$ Termasuk dalam aspek mu'amalah Islam lebih banyak hanya meletakkan prinsip-prinsip dasar (nilai) dan karena itu interpretasi terhadap maksud teks atau naskah adalah suatu kebutuhan. ${ }^{3}$

Manusia dalam memenuhi kebutuhan hidupnya seringkali tidak dapat dicukupkan hanya dengan apa yang dia miliki. Karenanya ia memerlukan hubungan dengan orang lainuntuk saling memberikan manfaat dari adanya hubungan tersebut. Untuk itulah Islam meletakkan prinsip hubungan antar manusia di atas paradigma "saling tolong menolong" agar adanya kemanfaatan (mashlahah) di dalam hubungan bermu'amalah.

Utang-piutang merupakan bagian yang penting dalam bermu'amalah dan dalam rangka paradigma di atas. Al-Qur'an membuat prinsip utang-piutang tersebut surat Al-Baqarah dari ayat $181-183$.

Dengan prinsip tolong menolong dapat dipahami bahwa utangpiutang dalam pandangan Islam tidak dibenarkan bersifat memberatkan, menyusahkan, dan kerusakan pada pihak yang berutang, tetapi dianjurkan untuk memberi kelonggaran apabila orang yang berutang benar-benar tidak mampu. Oleh sebab itu, mmeberi utang kepada orang yang benar-benar membutuhkan

${ }^{1}$ Harun Nasution, Islam Rasional, Mizan: Bandung 1995, hal.33.

2 M. Muslehuddin. Islamic Law and Social Change, Kamsi dan Yudian,W.A., ke Arah Figh Indonesia, FSHI, Fak Syariah IAIN SUKA, Yogyakarta, 1994, hal.88.

${ }^{3}$ M. Muslehuddin, Philosophy of Islamic Law and The Orientalis: A. Comparative Study of Islamic Legal System, Terj. Yudian. W.A., Tiara Wacana, Yogyakarta, 1991. 
dapat bernilai ibadah dan dalam waktu yang sama dapat bernilai kemanusian yang mulia. ${ }^{4}$

Dua deminsi diatas, terkait dengan dua ruang lingkup persoalan. Deminsi ibadah merupakan illat dilarangnya riba dalam utang-piutang dan mu'amalat lainnya. Karena aspek ibadah tidak boleh dikotori oleh keinginan nafsu yang tidak baik. Pada deminsi kemanusiaan terkait dengan hajat sosial dan kemiskinan yang harus mendapatkan perhatian dari kemaslahatan bersama dalam hidup bermasyarakat, karenya orang yang terlilit utang ditempatkan dalam kelompok "asnaf" yang delapan yang boleh menerima sedeqah, infaq dan zakat.

Dalam demensi kemanusiaan inilah utang-piutang mengalami elaborasi baik dalam pemaknaan maupun prosedural, seperti harus adanya penulisan dan jaminan.

Perjanjian utang-piutang dengan jaminan dikenal dalam AlQur'an dengan istilah al-rahn, biasanya diterjemahkan dengan "gadai". Ayat-ayat tersebut secara berurutan terdapat dalam surah Al-Baqarah dengan prinsip:

1) Dalam perjanjian hutang tidak dibenarkan mengambil riba (AlBaqarah: 273-280)

2) Perjanjian hutang hendaknya ditulis (Al-Baqarah: 282)

3) Bila diperlukan dalam aspek utang-piutang dapat diikutkan dengan jaminan (Al-Baqarah: 283)

Di kalangan fukaha utang-piutang biasanya kadang diidentikan dengan pinjam-meninjam, karena itu fukaha mendefinisakan dengan utang-piutang atau pinjam-meminjamadalah transaksi antara duan pihak, yang satu menyerahkan uangnya kepada orang

4 A. Azhar Basyir, Hukum Islam Tentang Riba, Utang-piutang, Gadai, Al-Ma'arif, Bandung, 1983, Hal.35. 
lian secara sukarela untuk dikembalikan lagi kepadanya oleh pihak kedua dengan hal yang serupa. Atau seseorang menyerahkan uang kepada pihak lain untuk dimanfaatkan dan kemudian mengembalikan penggantinya. ${ }^{5}$ Menurut jumhur Fakuha apa yang sah untuk diperjual-belikan, maka sah pula untuk diutangkan, baik barang yang dapat ditukar atau ditimbang maupun berupa uang.

Perjanjian utang-piutang merupakan perjanjian memberikan milik kepada orang lian. Pihak yang berutang merupakan pemilik atas utang yang diterimanya. Karena ia merupakn perjanjian atau transaksi (akad), maka unsur yang terpenting di dalamnya adalah proses akad yakni ijab kabul yang berisi pernyataan kehendak dari kedua belah pihak.

Memberikan utang dan atau pinjaman kepada orang yang membutuhkan adalah sunnah, dan hukum mencari utang atau pinjaman bukanlah suatu yang makruh. ${ }^{6}$ Al-Qur'an memuji pemberi utang yang suka memafkan utang orang lain apabila orang yang berutang mengalimi kesulitan ekonomi (Al-Baqarah: 280).

Walaupn transaksi utaang-piutang menghandung sifat dan nilai yang sama dengan orang yang memberi sadakah tetapi tidak sepenuhnya dianggap mempunyai sifat ikatan sukarela sebab disitu ada kewajiban dan tanggung jawab. Supaya tujuan kemashlahataan dari transaksi utang-piutang dapat merealisasikan fungsi kemanusiaan. Islam membolekan adanya persyaratan yang berfungsi prosedural. Dari aspek inilah sistem

5 Abu Syar'i. AH, Ar-riba Wa al-Qurudl, Terj. Ikhlas, Surabaya, 1993, hal. 125.

6 Taqyuddin An-Nabhani, An-Nidlam al-iqtishadi Fi Islam, Dar al Ummah, Beirut, 1990, hal. 203 
kredit dalam utang-piutang berkembang dalam dunia ekonomi modern. perkembangan ini tidak hanya menyangkut piham pemberi hutang dan yang berhutang yang pada awalnya masih dalam interaksi orang perorang, tetapi kini ,telah berkembang menjadi interaksi orang dalam institusi keuangan medern yaitu perbankan serta antar institusi pelaku ekonomi.

b. Cacat Kehendak pada Akad (perjanjian) dalam Hukum Islam 1. Perjanjian (Akad) dalam Hukum Islam

Istilah akd berasal dari istilah arab (aqdu) yang berarti transaksi, perikatan, atau perjanjian dan permufakatan. ${ }^{7}$ Akad juga berarti janji serta segala hal yang menunjukan ikatan untuk melakukan atau tidak melakukan suatu hal, baik sesuai dengan hukum atau tidak. 8

Menurut istilah fiqh bermakna

$$
\text { إرتباط إيجاب بقبولٍ علي وجه مشروع يظهر أثر في محله }
$$

9 (perikatan antara ijab dan qabul dengan cara yang dibenarkan oleh syara' dibuktukan dengan adanya akibat hukum pada obyeknya).

Fuqaha sepakat bahwa akad adalah pertautan antara ijab (kehendak untuk sesuatu kesepakatan) dengan qabul (kesepakatan atas kehendak sesuatu) yang diisyaratkan dengan kata-kataatau isyarat lainnya dan menunjukan maksud yang disepakati antara kedua belah pihak yang berkehendak dan bersepakat. 10

7 A. Rahman R, Ensikopledi Hukum Islam, Ikhtiar Baru, Van Hoeve, Jakarta, 1997, hal, 63.

8 Asy-Syaukani, Fath al-Qadir, Musthafa al-Babalhalabi, Mesir, TT, hal, 4.

9 Ahmad, Abu Al-Fath, Kitab Mu'amalat fi al-Syari'ata al-Islamiyah wa al-Qawamir, Matba'ah al Busfus, Mesir, 1913, I, hal. 139.

10 M. Salam Madkar, Al-Fath al-Islami, Maktabatul al Abdillah Wahbah, 1995, hal. 352. 
Dengan demikian, perjanjian atau akad secara esensial berisi pernyataan kehendak dari pihak tertentu untuk memberikan hak dan kewajibannya sesuai dengan kesepakatan.

Pernyataan kehendak yang disepakati dapat berupa pinjam-meminjam, Utang-piutang, juan beli, sewa-menyewa dan lain-lain. Pada pernyataan kehendak yang telah disepakati dalam akad terdapat klausul-klausul atau materi yang harus dipenuhi kedua belah pihak. Selain klausul akad tersebut sesuai dengan pernyataan kedua belah pihak, hak dan kewajiban dari materi akad tersebut wajib dipenuhi. Pengingkaran terhadap hak dan kewajiban dalam akad akan berakibat sanksi hukum berlaku pada pihak yang mengingkari. Tetapi bila pengingkaran itu disebabkan oleh sesuatu yang dibenarkan oleh hukum, maka pihak yang mengingkari akan terlindungi oleh hukum itu sendiri dengan sebab-sebab tertentu.

Dalam Islam sebab-sebab tertentu itu bisa disebut dengan istilah cacat ('uyub). Apabila kesepakatan kehendak para pihak tidak murni atau dengan kata lain terdapat cacat ( gebrekhiq) sekalipun secara tersembunyi sehingga persetujuan/ kesepakatan para pihak tersebut menjadi tidak sempurna, maka perjanjian yang dibuat para pihak dapat dibatalkan meskipun sudah lahir pernyataan kehendak secara sah. ${ }^{11}$ Sebaliknya apabila telah terjadi pernyataan dan kesepakatan dengan kehendak murni, pengingkaran yang terjadi akan menimbulkan sanksi hukum yang mengingkari.

Kehendak murni adalah kehendak yang dinyatakan secara bebas dan suasana yang wajar serta tidak dipengaruhi oleh unsur-unsur yang menyesatkan klausul-klausul dan

\footnotetext{
${ }^{11}$ M. Yahya Harahap, Segi-segi Hukum Perjanjian, Alumni, Bandung, 1982, hal.25
} 
merusak kehendak para pihak. Hal-hal menyesatkan dan membuat kehendak menjadi cacat dengan sebab itu perjanjian yang dibuat berdasarkan kepadanya menjadi cacat kehendak ('uyub al-Rida). ${ }^{12}$

2. Cacat Kehendak ('uyub al-Rida/Wilsgebrek)

Dalam islsam cacat kehendak itu, karena adanya kemaafan dari dan atau kebolehan untuk mengingkari perjanjian yang disebabkan oleh:

a. Kekhilafan (al-Kharda)

b. Paksaan (al-ikrah)

c. Penipuan (Gassyai) ${ }^{13}$

Sebagaimana dalam hukum Islam dalam KUH Perdata. Indonesia Ps 1321, menjelaskan bahwa cacat kehendak itu ada tiga macam, yaitu kekhilafan (dwaling), paksaan (dwang), dan penipuan (bedrog). Dalam ilmu hukum ditambahkan pulaketidak seimbangan prestasi yang mencolok senagai unsur yang menyebabkan perjanjian dapat dibatalkan dalam hal-hal tertentu ${ }^{14}$. Ahli-ahli hukum Belanda menyatakan penyalahgunaan keadaan (misbruik van de omstandigheden) sebagai suati bentuk cacat kehendak juga ${ }^{15}$.

Hukum Islam adalah hukum yang didasarkan pada nilai obyektifisme. Hal ini nampak dalam penekanannya pada akad sebagai pertautan ijab dab qabul yang menimbulkan akibat

12 As-Sanhuri, Abl. Razak, Nazariyah Al-Aqb, Dar al-Fikr, Beirut, TT, hal. 246

13 Samsul Anwar, Hukum perjanjian dalam Islam, Kajian Terhadap Risalah Perizinan dan Cacat Kehendak, Balai Penelitian IAIN SUKA, Yogyakarta, 1996, hal. 96.

14 As Sanhuri, Abl. Razak, Nazariayah Al-Aqd, Dar Al-Fikr, Bairut, TT, hal. 246

15 J. Satrio, Hukum Perikatan: Perikatan yang Lahir Dari Penrjanjian. I,. Citra Aditya Bakti Bandung, 1995, hal. 316 
hukum pada objek akad dan kecendrungan kepada keadaan yang nyata. Oleh karena itu semakin objektif sifat dan unsurunsur cacat kehendak itu semakin mendapat perhatian dalam ilmu hukum islam. Sebaliknya semakin subjektif semakin kurang mendapat perhatian. Bila diamati hirarki cacat kehendak tersebut dari yang paling subjektif kepada yang objektif maka dapat dilihat kekhilafan adalah paling subjektif sifatnya karena ia merupakan gambaran dari pikiran seseorang mengenai sesuatu tidak sebagaimana adanya, baru kemudian penipuan dan paksaan yang lebih konkrit dan objektid karena merupakan tindakan murni orang lain yang bersifat melawan hukum. Karena sifatnya yang amat subjektif, serta kekhilafan tidak mendapat tempat yang menonjol dalam hukum Islam ia tersebar di sejumlah tempat dalam berbagai jenis "khiyar" tanpa dihimpun dalam satu kesatuan yang bulat dan disebut teori tentang kekhilafan.

Bila cacat kehendak telah terjadi dalam perjanjian (akad), kedua belah pihak diberikan pilihan alternatif yang disebut dengan hak khiyar dan pihak yang bercacat kehendak diberi kebebasan untuk memilih, apakah meneruskan akad atau membatalkan, karena maksud hak khiyar pada hakikatnya adalah untuk pilihan terhadap alternatif yang baik. ${ }^{16}$

Dari aspek Syar'i cacat kehendak itu terjadi sangat berhubungan dengan kesesuaian antara ijab dan qabul dalam akad baik secara zhahiri maupin bathini. Oleh karena itu, pihak yang berqabul mempunyai hak khiyar kabul (Khiyat Al-Qabul)

16 M. Yusuf Musa, Al-Figh Al Islami li Dirasati al-Nizam al-Mu'amalah Fiqh, Dar Kitab Al-Arabi, Mesir, 1958, hal. 459. 
dan pihak yang membuat ijab juga mempunyai hak khiyar yang disebut khiyar Raju'. Hak ini diberikan pada prinsipnya untuk menjaga agar tidak ada pihak yang dirugikan dalam suatu perjanjian atau transaksi. ${ }^{17}$

\section{Cacat Kehendak Kekhilafan}

Kekhilafan adalah suatu keadaan dalam diri seseorang yang mendorongnya untuk menggambarkan sesuatu tidak sebagaimana mestinya.18 Atau gambaran keliru (dalam aspek kehendak) pada salah satu pihak terhadap objek atau pihak lawan dalam perjanjian. ${ }^{19}$ gambaran keliri inilah yang membuat ketidaksesuaian dengan apa yang dikehendaki dalam akad.

Dalam hukum Islam, kekhilafan dapat terjadi pada benda, prosedur, dan pada subjek akad. Kekhilafan pada benda dapat mengakibatkan akad batal demi hukum atau dibatalkan, sedangkan kekhifan pada prosedural dan subjek dapat berakibat akad dapat dibatalkan dengan mempergunakan khiyar 'aib. Sedangkan kekhilafan pada prosedural dan subjek dapat berakibat akad dapat dibatalkan dengan mempergunakan hak khiyar Al-Wasf (hak untuk meneruskan atau membatalkan akad karena tiadanya sifat yang diinginkan pada objek akad).

Ada tiga macam metode untuk mengatahui terjadinya kekhilafan. Petama, ia menjelaskan maksudnya secara

17 Al.Babarti. Syarh al-Inayah 'ala al-Hidayah, Dar al Fikr, Beirut, 1977, hal.253.

18 As-Sanhuri, Abl Razak, Nazariyah al-Aqd, Dar al-Fikr, Beirut, TT, hal. 350.

19 J. Satrio, Hukum Perikatan: Perikatan yang Lahir dari Perjanjian, I, Citra Aditya Bakti, Bandung, 1995, hal 293. 
tegas. Kedua, disimpulkan dari situasi. Ketiga, disimpulakn dari sifat hakikat sesuatu. ${ }^{20}$

Hukum Islam juga mendekati kekhilafan tersebut melalui konsep Khiyar Ar-ru'yah, pembatalan akad dimungkinkan terjadi apabila salah satu pihak baru mengatahui atau melihat objek akad setelah akad telah terjadi. ${ }^{21}$

Penggunaan hak khiyar ru'yah dibenarkan dengan pertimbangan kema'afan yang disebabkan oleh salah satu pihak belum mengatahui atau melihat objek akad.

\section{Cacat Kehendak Paksaan}

Dalam hukum Islam paksaan adalah bentuk tekanan atau ancaman terhadap seseorang dengan mengunakan caracara yang menakutkan, agar seseorang terdorong untuk melakukan atau tidak melakukan sesuatu. ${ }^{22}$

Paksaan merupakan unsur cacat kehendak yang paling menonjol karena sifatnya konkrit dan dapat dirasakan oleh masing-masing pihak. Bentuk paksaan ini ada dua macam: paksaan berat (ad-ikrah al-mulji) dan paksaan ringan (alikrah ghairu al mulji). Paling tidak ada tiga unsur paksaan yang dapat menimbulkan akibat hukum: ancaman yang ditekankan tidak mampu untuk dipikul atau sangat menberatkan, ancaman bersifat segera sehingga ia tidak memiliki kemingkinan untuk lolos dari ancaman, ancaman

20 As Sanhuri, Masadir al-Haq Fi al-Fiqh al Islami, Dirasah al Munqaranatu al- Fiqh al-Garbi, Dar al-Hana, 1954, II, hal. 130.

${ }^{21}$ Az Zuhaily, Wahbah, Al Fiqh al-Islami wa al adillatuhu, dar Al-Fikr, Damascus, 1989, hal. 267-275.

22 Az Zarqa, Musthafa Ahmad, Al Fiqh al-Islami al-Jadid, Dar al-Fikr, Beirut, 1968, hal. 368. 
tersebut tanpa hak hukum dan merupakan tindakan yang tidak sah. ${ }^{23}$

3. Cacat Kehendak Penipuan

Penipuan yang menimbulkan akibat hukum pada dasarnya lebih konkrit dari pada kekhilafan karena kekhilafan merupakan keadaan yang sangat subjektif terjadi pada salah satu pihak, sebaliknya penipuan adalah adanya unsur kesengajaan untuk menyimpang dari esensi akad.

Ahli-ahli hukum Islam mendefinisikan penipuan sebagai tindakan mengelabui oleh salah satu pihak terhadap pihak lain dengan perkataan atau perbuatan bohong untuk mendorongnya memberikan sesuatu atau objek akad tertentu. ${ }^{24}$

Oleh sebab itu penipuan tidak bisa dipersangkakan tetapi harus dibuktikan, dengan bukti itulah cacat kehendak diberlakukan untuk pembatalan akad. Unsur penipuan meliputi: a. Adanya tipu muslihat, dan b. Tipu muslihat itu mendorong pihak tertipu untuk memberikan suatu persetujuan perizinan. Tipu muslihat bisa terjadi dalam berbagai tempat, baik terhadap materi akad maupun dalam proses (prosedure) terjadinya akad.

Ada dua jenis penipuan yakni at-tagrir al-fi'ly dan at-tagrir al-qauly. Menyembunyikan keterangan atau tidak menjelaskan sesuatu yang seharusnya dijelaskan termasuk dalam kategori penipuan karena secara sengaja

${ }^{23} \mathrm{Az}$ Zuhaily, Wahbah, Al Fiqh al-Islami wa al adillatuhu, Dar Fikr, Damascus, 1989, hal. 314-315.

${ }^{24}$ Az Zarqa, Musthafa Ahmad, Al Fiqh Al Islami al-Jadid, Dar al Fikr, Beirut, 1968, hal. 374., Az Zuhaily, Wahbah, Al Fiqh al Islami wa al Adillatuhu, Dar al-Fikr, Damascus, 1989, hal. 218. 
menyembunyikan sesuatu yang seharusnya diketahui oleh pihak lain dalam perjanjian.

\section{Simpulan}

Cacat kehendak yang memungkinkan terjadinya pembatalan akad sangat terkait dengan esensial suatu akad. Karena akad pada dasarnya merupakan pemcerminan dari kehendak esensial tersebut. Apabila esensial akad tidak tercapai, akad dapat dibatalkan. Logika ini dalam hukum Islam didukung oleh kaidah Fiqh:

$$
\text { العبرة في العقود للمقاصد و المعاني لالألفاظو المباني }
$$

Yang dianggap dalam akad adalah maksud-maksud dan makanmakna bukan lafazh-lafazh dan bentuk. ${ }^{25}$

Pada dasarnya kerangka teori ini lebih cendrung pada pendekatan mashalahah-murshalah dan pendekatan seperti ini seleras dengan pendepat Az-Zuhaily yang menyatakan bahwa Allah telah meletakan dalam setiap hukumnya rahasia yang dapat mendatangkan kemashalatan manusia. dengan demikian, syari'at itu pada dasarnya untuk mewujudkan tujuan umum dalam alam nyata yaitu membahagiakan individu dan masyarakat, memelihara serta menyemarakkan dunia dengan segenap sarana yang akan menyampaikan kepada jenjang kesempurnaan, kebaikan, budaya dan peradaban yang paling menonjol ${ }^{26}$.

25 Abd. Mujib, Qawaidu al-Fiqh al-Islami, Nur Cahaya, Yogyakarta, 1980, hal. 24. 26 Az-Zuhaily, Wahbah, Nazariyah al-Dharurah al-syar'iyah, Muqaranatu Ma'a al-

Qarun al Wadh’i, Terj, Gaya Media Pratama, Jakarta, 1997, hal. 47. 


\section{Daftar Pustaka}

Az Zuhaily, Wahbah, Al Fiqh al-Islami wa al adillatuhu, dar AlFikr, Damascus, 1989.

Az Zarqa, Musthafa Ahmad, Al Fiqh Al Islami al-Jadid, Dar al Fikr, Beirut, 1968.

Abd. Mujib, Qawaidu al-Fiqh al-Islami, Nur Cahaya, Yogyakarta, 1980.

Az-Zuhaily, Wahbah, Nazariyah al-Dharurah al-syar'iyah , Muqaranatu Ma'a al-Qarun al Wadh'i, Terj, Gaya Media Pratama, Jakarta, 1997.

An-Nabhani, Taqyuddin, An-Nidlam al-iqtishadi Fi Islam, Dar al Ummah, Beirut, 1990.

Asy-Syaukani, Fath al-Qadir, Musthafa al-Babalhalabi, Mesir, TT.

As-Sanhuri, Abl. Razak, Nazariyah Al-Aqb, Dar al-Fikr, Beirut, TT.

Ahmad, Abu Al-Fath, Kitab Mu'amalat fi al-Syari'ata al-Islamiyah wa al-Qawamir, Matba'ah al Busfus, Mesir, 1913.

Anwar, Samsul, Hukum perjanjian dalam Islam, Kajian Terhadap Risalah Perizinan dan Cacat Kehendak, Balai Penelitian IAIN SUKA, Yogyakarta, 1996

Al.Babarti. Syarh al-Inayah 'ala al-Hidayah, Dar al Fikr, Beirut, 1977.

As Sanhuri, Masadir al-Haq Fi al-Fiqh al Islami, Dirasah al Munqaranatu al- Fiqh al-Garbi, Dar al-Hana, 1954, II.

Basyir, A. Azhar, Hukum Islam Tentang Riba, Utang-piutang, Gadai, Al-Ma'arif, Bandung, 1983.

Harahap, M. Yahya, Segi-segi Hukum Perjanjian, Alumni, Bandung, 1982. 
Muslehuddin, M. Islamic Law and Social Change, Kamsi dan Yudian,W.A., ke Arah Fiqh Indonesia, FSHI, Fak Syariah IAIN SUKA, Yogyakarta, 1994.

Muslehuddin, M, Philosophy of Islamic Law and The Orientalis: A. Comparative Study of Islamic Legal System, Terj. Yudian. W.A., Tiara Wacana, Yogyakarta, 1991.

Musa, M. Yusuf, Al-Figh Al Islami li Dirasati al-Nizam alMu'amalah Fiqh, Dar Kitab Al-Arabi, Mesir, 1958.

Madkar, M. Salam, Al-Fath al-Islami, Maktabatul al Abdillah Wahbah, 1995.

Nasution, Harun, Islam Rasional, Mizan: Bandung 1995.

Rahman A. R, Ensikopledi Hukum Islam, Ikhtiar Baru, Van Hoeve, Jakarta, 1997.

Syar'i, Abu, Ar-riba Wa al-Qurudl, Terj. Ikhlas, Surabaya, 1993.

Satrio, J, Hukum Perikatan : Perikatan yang Lahir Dari Penrjanjian. I,. Citra Aditya Bakti Bandung, 1995. 